\title{
A INSUPORTÁVEL CONTENÇÃO: ClARICE LISPECTOR E KATHERINE MANSFIELD
}

\author{
RICARDO IANNACE *
}

RESUMO: Trata-se de um estudo comparado dos contos "Amor", de Clarice Lispector, e "Bliss", de Katherine Mansficld. Os conceitos do historiador da literatura Mikhail Bakhtin acerca de dialogismo e polifonia dão suporte teórico à análise das duas narrativas, cujas personagens centrais figuram esposas da média burguesia que, ao se defrontarem com insólitas experiências, deixam transparecer seus reservados conflitos existenciais. PALAVRAS-CHAVE: Feminino; Intertextualidade; Bakhtin; Dialogismo; Polifonia

Clarice Lispector, em crônica intitulada "O primeiro livro de cada uma de minhas vidas", escrita ao Jornal do Brasil de 24 de fevereiro de 1973, menciona em meio a um afetuoso discurso memorialista algumas das ficções que lera na infầncia e adolescência, as quais the deixaram, inevitavelmente, expressivas marcas. Na verdade, algumas delas parecem jamais ter-se desalojado do imaginário da leitora ucraniana de ascendência judaica, que sempre, quando indagada acerca de suas origens, manifestava estreito apego pelo Brasil e pela língua portuguesa. Porque foi nesta lingua que se alfabetizou e leu obras nacionais e estrangeiras, em parte responsáveis por fazê-la apreender, codificar e decodificar o mundo - a seu ver abstrato, misterioso - do qual se constituiu, a posteriori, sua matéria ficcional.

E em uma de suas vidas, enuncia ter-lhe passado pelas mãos "um livro fininho que contava a história do patinho feio e da lâmpada de Aladim"; seguido, mais adiante, por Reinações de Narizinho de Monteiro Lobato; depois, pelo Lobo da Estepe de Herman Hesse, que levou a adolescente leitora de catorze

* Mestrando em Literaanos a escrever "um longo conto imitando-o", até descobrir um diferente volume sobre o balcão de uma livraria: 
[...] aos quinze anos, com o primeiro dinheiro ganho com o trabalho meu, entrei altiva porque tinha dinheiro, numa livraria, que me pareceu o mundo onde eu gostaria de morar. Folheei quase todos os livros dos balcões, lia algumas linhas e passava para outro. E de repente, um dos livros que abri continha frases tão diferentes que fiquei lendo, presa, ali mesmo. Emocionada, eu pensava: mas esse livro sou eu! E, contendo um estremecimento de profunda emoção, comprei-o. Só depois vim a saber que a autora não era anônima, sendo, ao contrário, considerada um dos melhores escritores de sua época: Katherine Mansfield. ${ }^{\perp}$

E é também de maneira altiva que Berta, personagem central de um dos contos do livro folheado por Clarice, entra em sua casa após, fortuitamente, absorver os últimos raios de sol da tarde. Essa sensação da personagem, eixo motriz da narrativa de Katherine Mansfield, é de êxtase e plenitude. "Bliss": título que a escritora neozelandesa deu ao seu conto, traduzido, em português, por "Felicidade".

Mas o que haveria de especial na obra exposta sobre o balcão a ponto de despertar tanto fascínio em Clarice? Afinal, essa identificação com a contista que "não era anônima" não se esvaiu naquele efusivo momento de descoberta da obra. Certamente, o fato de descobrir-se no objeto literário já comprovava a precoce predileção da fruidora pelo rondar da palavra em torno da alma feminina, deixando-se vagar em redor de instáveis relações sociais e conjugais, fisgando instantes mágicos e desconhecidos do próprio ser. Pois esses singulares caminhos, por onde deslizam as palavras na escritura de Katherine, fixaramse, também, na literatura de Clarice, cuja composição textual afina-se com a da escritora de língua inglesa. Cum efeito, em território nacional foi nossa autora quem bem registrou os complexos laços... de família.

Laços de Familia. Assim se intitula o livro de contos de Clarice Lispector publicado em 1960. O volume reúne treze histórias que gravitam em redor de tensas cenas familiares, cujos núcleos comprimem reveladores mal-estares, não só experienciados pelos leitores mas, sobretudo, experimentados pelas personagens que, a rigor, se mantêm presas às amarras criadas para si mesmas. Nesse exemplar, encontra-se, em especial, uma narrativa que permite estabelecer, sob certa perspectiva, a comparação entre as duas consagradas escritoras. $\mathrm{Ou}$ melhor, que admite um estudo dialógico e polifônico - de ótica bakhtiniana entre os escritos dessas construtoras de nebulosas atmosferas.

Em "Amor", 2 bem como em "Bliss", vêem-se personagens femininas sufocadas, à meia-luz do dia, por seus universos familiares - lar, marido ou filhos são quem determina direta ou indiretamente a relação que estas mulheres devem ter consigo mesmas e com aqueles com os quais convivem, tudo de modo a fazê-las solidificar os densos enlaces domésticos e sociais, praticamente danificados, mas que, no fundo, as aprisionam. É como se o cumprimento de determinados papéis não só viesse a lhes impossibilitar o completo alcance da liberdade como, ainda, as levasse a forjar aos olhos de outrem (e a seus próprios
(1) Clarice LISPECTOR, "O primeiro livro de cada uma de minhas vidas", in A Descaberta do Mundo, 3a. ed., Rio de Janeiro, Francisco Alves, 1992, p. 491 492.

(2) In Laços de Familia, 3a. ed., Rio de Janeiro, Editora do Autor, 1965. (Quando fizermcs citações do conto enfeixado nesta obra, indicaremos o número da página desta edição.)

(3) In Felicidade, trad. Érico Veríssimo, Rio de Janeiro, Nova Fronteira, [s.d.]. (As citações que faremos de "Bliss" corresponderão ao número da página desta edição.) 
olhos) um aparente equilíbrio interior, gerenciador de controlada estabilidade familiar e conjugal. Desta forma, é em reservados momentos da vida das personagens, como quando se aquecem para receber em suas casas amigos ou familiares, que se propaga a asfixiante existência destas anfitriãs. Pois curtos e precisos intervalos temporais bastam para trazer à tona os mais secretos e inquietantes sintomas de ordem emocional.

\section{DUAS MULHERES, DOIS JANTARES}

No conto "Amor", o narrador, posicionado na terceira pessoa e contagiado pela voz da memória de Ana, participa ao leitor o dificil trajeto trilhado pela personagem no caminho de volta para casa, após ter realizado suas compras. Ana, recostando-se no banco do bonde à procura de conforto, jamais poderia prever a inesperada surpresa que receberia naquele atípico final de tarde, longe dos firmes alicerces que sustentam seu apartamento e a privam de qualquer encontro revelador; porque, sem forças no momento para receber a súbita agressão da natureza, só dispunha, em uma das mãos, de um "novo saco de tricô", onde carregava um embrulho de ovos. À noite, receberia a visita dos irmãos para o jantar.

Mesmo enfrentando os "conciliáveis" contratempos do dia-a-dia, a vida The era aparentemente calma. Os "filhos de Ana eram bons [...]. Cresciam, tomavam banho, exigiam para si [...]. A cozinha era enfim espaçosa, o fogão enguiçado dava estouros. $O$ calor era forte no apartamento que estavam aos poucos pagando. Mas o vento batendo nas cortinas que ela mesma cortara lembrava-lhe que se quisesse podia parar e enxugar a testa, olhando o calmo horizonte. [...] Ela plantara as sementes que tinha na mão, não outras, mas essas apenas. E cresciam árvores. Crescia sua rápida conversa com o cobrador de luz, crescia a água enchendo o tanque, cresciam seus filhos, crescia a mesa com comidas, o marido chegando com os jornais e sorrindo de fome, o canto importuno das empregadas no edificio. Ana dava a tudo, tranqüilamente, sua mão pequena e forte, sua corrente de vida" (p. 15).

É, portanto, essa "corrente de vida" que garante a estabilidade da rotina familiar, da mesma forma que favorece o adiamento de explosivos distúrbios emocionais. Ana, ao render-se a ritualísticos afazeres domésticos, passa paulatinamente a anular seus vitais impulsos humanos, privando-se de enxergar o mundo à margem do estreito e reduzido reduto caseiro. Pois, uma vez que a conquista da perigosa liberdade implica o imediato rompimento com o que se convencionou correto em uma sociedade burguesa patriarcal, a personagem prefere antes seguir o mais seguro trilho de sua vida, limitando-se apenas a regar as "verdadeiras" sementes que plantara. Dai viver em constante vigilância, isto é, acompanhando a desenvoltura dos filhos e a diária manutenção da casa, evitando gastos à primeira mão desnecessários, como o conserto do fogão 
"enguiçado" que dá estouros, a compra de cortinas que, sem ao menos precisar confeccioná-las, ornamentariam a sala de seu apartamento, que "aos poucos" vai sendo pago... Tudo, enfim, conforme o mais justo regulamento de mãe e esposa equilibrada, que, sem sublevar-se, dá seguimento a uma aparente normalidade.

Mas, tal como o fogão da personagem, o que propriamente reside no seu intimo são leves estouros. Estouros que se intensificam e abalam a já trincada estrutura psíquica de Ana no momento em que ela avista, do banco do bonde, "o homem parado no ponto", dado que a "diferença entre ele e os outros é que ele estava realmente parado. De pé, suas mãos se mantinham avançadas. Era um cego" (p. 17). Um cego mascando chicle de olhos abertos na escuridão.

Ao deparar-se com o anônimo personagem, que, do nada, aparece para levá-la ao "pior" de si mesma, concretiza-se o agudo estouro no até então manso, mas sensivelmente perturbado, interior da protagonista. Porque após o expressivo grito dessa assustada passageira, que distraida vislumbra o transeunte e é arremessada para trás do banco, permitindo que a brusca arrancada do bonde ocasione a queda e quebra do embrulho de ovos, instaura-se, na narrativa, o ingresso de Ana num desconcertante mundo: violável e indesejado, que agora a grotesca figura do cego faz emergir. E, pois, graças a súbitas leis (da gravidade, do "homem") que se torna inevitável o mergulho da protagonista na sua mais profunda verdade e identidade. O cego, metáfora da escuridão, da invisibilidade, é quem, de repente, ateará uma centelha aos sentidos daquela que até pouco tempo atrás era uma contida mulher.

Com certeza, é o fato de olhar o insólito homem, previamente "solto", desamparado, mas em contrapartida seguro de si, o que mais a perturba. De fato, é neste substantivo instante epifânico do conto que, descompassadamente, afloram no íntimo da personagem os mais pulsivos questionamentos, a ponto de fazê-la considerar que aqueles seres "verdadeiros": o marido, os filhos aos quais dedicara talvez sua fatia mais significativa da vida, não the proporcionavam a segurança capaz de suprir a tão desconfortante ansiedade. ${ }^{4}$ Até porque o revelador encontro com o outro resultou na confirmação de que a protagonista não dispunha de liberdade igual à daquele cego, entregue, sem constrangimento, à agitação das ruas, ao contrário dela, que "apaziguara tão bem a vida, cuidara tanto para que esta não explodisse" (p. 19). Ademais, não estaria Ana mais cega do que o homem contemplado, sujeita, conforme optara, a uma espécie de vida em clausura? ("Assim ela o quisera e escolhera.") Ou não seria aquela gratuita aparição, efetivamente, a prova de que a vida ultrapassa o "bem", abeira-se do abismo? E ainda, por que bem aquele "pobre" cego seria o emblema do "mal"? Justamente ele, de quem por um instante quase sentira ódio, mas a seguir piedade, como uma mãe que se vê ávida por proteger um filho disperso na multidão?

E, como uma cega desgovernada, só então percebe "que há muito passara do seu ponto de descida", saltando do bonde em "uma rua comprida, com
(4) Sobre a epifania em Clarice Lispector, ver: 1) Olga de $\mathrm{SA}, A$ Escritura de Clarice Lispector, Petrópolis, Vozes; Lorena, FATEA, 1979. 2) Affonso Romano de SANT'ANNA, "O ritual epifânico do texto", in Clarice LISPECTOR, A Paixão Segundo G.H., edição crítica, coord. Benedito Nunes, Paris, Association Archives de la litté rature latino-américaine, des Caraibes et africaine du XXème siècle; Brasilia, $\mathrm{CNPq}$, 1980, p. 237-257. 
(s) Benedito NUNES, "A forma do conto", in $O$ Drama da Linguagem. Uma leitura de Clarice Lispector, São Paulo, Ática, 1989, p. 85 (Série Temas, v. 12). muros altos, amarelos". Ao andar "mais ao longo de uma sebe", atravessa "os portōes do Jardim Botânico", sentando-se em um dos bancos do Jardim por sinal, "tão bonito que ela teve medo do inferno". É quando tudo ao seu redor parece se transformar e adquirir nova significação, a natureza reveste-se de novas cores: "Tudo era estranho, suave demais, grande demais." Pois conforme assinalou o crítico e ensaísta Benedito Nunes, "ali, em ação nas árvores silenciosas, desencadeia-se algo hostil que o cego lhe revelara, e que, agora, fascinada, experimentando um estado de verdadeiro êxtase, vê estender-se sobre o mundo inteiro."5

Inquieta, olhou em seu tomo. Os ramos se balançavam, as sombras vacilavam no chão. Um pardal cismava na terra. E de repente, com mal-estar, pareceu-lhe ter caído numa emboscada. Fazia-se no jardim um trabalho secreto do qual ela começava a se aperceber. Nas árvores as frutas eram pretas, doce como mel. Havia no chão caroços secos cheios de circunvoluçōes, como pequenos cérebros apodrecidos. $O$ banco estava manchado de sucos roxos. Com suavidade intensa rumorejavam as águas. No tronco da árvore pregavam-se as luxuosas patas de uma aranha. A crueza do mundo era tranqüila. $O$ assassinato era profundo. E a morte não era o que pensávamos. (p. 20-21)

Mas esse estado de deslumbramento e estranhamento tem o seu limite. Ana refreia esta perigosa experiência que poderia levá-la ainda mais a recônditas esferas, quando se dá conta dos compromissos interrompidos. Assustada, às pressas abandona aquele maravilhoso e ao mesmo tempo traiçoeiro lugar, regressando à sua casa e entregando-se àqueles "inofensivos" seres, sobre os quais ainda exercia, de certo modo, algum controle. Não é à toa que, ao entrar em seu apartamento e rever o filho, dả-lhe um sôfrego abraço, como que se certificando da provisória posse de uma propriedade humana.

Com efeito, após essa estranha aprendizagem, que se iniciou na viagem de bonde e se desdobrou na extasiante experiência no Jardim Botânico, a personagem definitivamente retoma suas atividades, em um lar, diga-se de passagem, que jamais the seria o mesmo. E, auxiliando a empregada no preparo do jantar, "andava de um lado para outro na cozinha, cortando os bifes, mexendo o creme [...]." Assim, a mãe e esposa resgata sua velha função, porque mais tarde "o marido veio, vieram os irmãos e suas mulheres, vieram os filhos dos irmãos."

\section{Jantaram com as janelas todas abertas, no nono andar. (p. 24)}

Em "Bliss", narra-se um intrigante episódio da vida de Berta, uma personagem que a certa altura da vida se vê contagiada por uma estranha, extasiante e inexplicável comoção, que a teria levado à completa perda dos sentidos e a entregar-se sem reservas ao convidativo deslumbramento frente à sua feminilidade, se antes não sancionasse seus afligentes impulsos, responisáveis por fazê-la experienciar a dolorosa e prazerosa sensação de felicidade. 
Munido do discurso indireto livre, o narrador dessa história a exemplo do narrador do texto anterior entrelaça alternadamente ao seu enunciado a voz da personagem principal. Esta, sem dispor de fundamentadas justificativas para a incontida sensação que a invade, manifesta-se: "Que é que podemos fazer se temos trinta anos e, ao dobrar a nossa própria rua, somos invadidos por uma sensação de felicidade absoluta felicidade! como se tivéssemos de repente engolido um nútilo pedaço deste sol da tardinha e ele estivesse a arder em nosso peito, a despedir um chuveiro de minúsculas faíscas em todas as partículas do nosso ser, até nos dedos das mãos e dos pés?..." (p. 1).

Em realidade, o que mais surpreende a personagem é a insistente presença daquela brasa instalada em seu peito, justamente naquele significativo e planejado dia em que receberia para o jantar a visita de um grupo de amigos; em especial, a de uma nova amiga... Era "quase insuportável. Ela mal ousava respirar com medo de avivar mais o fogo com seu sopro, e no entanto respirava profundamente." Quanto mais se empenhava em dar forma aos arranjos da sala de jantar, mais aquela sensação se intensificava, e, maravilhada, contemplava sobre a mesa as "tangerinas e maçãs tingidas dum róseo de morango. Pêras amarelas, lisas como seda, uvas brancas cobertas duma tênue poeira de prata e mais um grande cacho de uvas cor de púrpura. Estas últimas haviam sido compradas para sintonizar com o tapete novo da sala de jantar" (p. 2).

Mas se, antes do anoitecer, Berta já se detinha a olhar embevecida as cores e a exuberância das frutas, vendo-as de uma maneira tão particular, como que transferindo a elas aquela extasiante sensação de que se via tomada, maior seria seu deslumbramento quando, após o jantar, se defrontaria tal como a personagem Ana do conto "Amor", no Jardim Botânico com a calma e a voragem da natureza em seu ostensivo e secreto mistério. Pois, ao ir à cozinha preparar o café, passa, paralisada, a contemplar ao lado da mais nova e intima amiga uma pereira florida, que se fazia ver através das "longas janelas" abertas. Miss Fulton e Berta, juntas, ali, numa correspondente cumplicidade.

E as duas mulheres ficaram uma ao lado da outra a contemplar a esguia árvore florida. Embora estivesse em absoluta quietude, ela dava a impressão de, como a chama de uma vela, espichar-se para o alto, apontar, tremer no ar puro, ficar cada vez mais alta aos olhos das duas amigas quase a tocar a borda da lua redonda e prateada.

Quanto tempo ficaram elas como presas no círculo daquela luz imaterial, compreendendo-se uma a outra perfeitamente, como criaturas dum outro mundo, a se perguntarem a si mesmas o que deviam fazer neste mundo com aquele tesouro de felicidade que thes ardia no peito e que lhes caia, em flores de prata, dos cabelos e das mäos? (p. 12)

Esta seria apenas uma das passagens da narrativa de Katherine Mansfield que nos remete ao conto "Amor", vista a estreita afinidade que, a rigor, pode ser estabelecida entre as protagonistas das duas histórias, entregues, como a mutável natureza, a sofrer, a certa hora do dia, o seu processo de revivificação. 
(פ Nádia Battella GOTLIB, Clarice - Uma Vida que se Conta, São Paulo, Ática, 1995, p. 135.
Portanto, considerar que "Amor" se constrói num plano paralelo ao conto "Bliss" significa depreendê-lo como um acabado intertexto, isto é, concentrado no núcleo temático e no processo de produção de efeitos estilisticos que Clarice, a seu modo, tem em comum com Katherine Mansfield. Dai a preferência de ambas as autoras por certos "ingredientes" ligados a uma natureza hostil, dignos de proporcionar às suas escrituras um caráter tanto de estranhamento quanto de familiaridade, sobretudo quando se justapõem numa única história elementos tão diferenciados.

Conforme registra a professora Nádia Battella Gotlib, "a 'identificação' que sente Clarice com Katherine manifesta-se em muitos detalhes de construção narrativa. Lembre-se de que Katherine sofre, entre outros tantos males físicos, da insociabilidade, do 'desenraizamento', ao mesmo tempo em que representa alegres e instantâneos flashes de um cotidiano singular, habitado por pombos, flores, árvore, cenas de família, lista de 'coisas' ou 'atos' a fazer no dia, galinhas, amigos, cozinheira, dificuldades do escrever, duas ou mais versões sobre um mesmo tema, morte, o inominável [...]." E a professora continua: "há, sobretudo, entre elas, a semelhança de uma incrível sensibilidade para registrar o êxtase que acompanha os momentos de crise de identidade, em que se fende a estrutura da vida familiar burguesa, mediante o vislumbre de um estranho e atraente território até então ignorado ou considerado sem importância. Clarice, tal como Katherine, experimentou a flagrância do êxtase, ou dos momentos de 'suspensão', ao bem registrar essas experiências femininas singulares, em momentos considerados bem especiais." 6

Até mesmo a forma de elaboração do discurso com que mais atrás a personagem Ana, dando vazão à voz do imaginário, constituía o seu moroso quadro familiar, não difere, propriamente, da mesma operada por Berta ao tentar se convencer de sua estabilidade conjugal e social:

Para falar a verdade, a verdade mesmo - tinha tudo. Era jovem, Harry e ela se amavam como sempre, entendiam-se esplendidamente e eram na realidade bons camaradas. Tinham um bebê adorável. [...] Possuiam aquela casa, aquele jardim e estavam em absoluto satisfeitos com ambas as coisas. Além disso, tinham boas relações - amigos modernos, vibrantes, escritores e pintores e poetas ou gente interessada em questões sociais-exatamente a espécie de amigos que ela desejava. E depois havia livros, música; ela descobrira uma costureirinha maravilhosa; eles iam viajar pelo estrangeiro no próximo verão e a nova cozinheira thes fazia as mais soberbas omeletes... (p. 6)

\section{E em outro momento da narrativa:}

Pela primeira vez em sua vida Berta Young desejou o marido.

Oh! ela o amava - ela o amara, sempre, estava claro, de outra maneira, mas não exatamente daquela. [...] Tinham discutido isso tantas vezes! No princípio ela ficara terrivelmente atormentada. Eles eram tão francos um com o outro, tão bons camaradas. (p. 13) 
A maneira como se narram os nevrálgicos instantes de insuportável contenção das personagens frente a dadas situações, bem como a cadência sonora, ritmada das frases, antes de tudo reforça o grau de parecença entre as duas escrituras isso sem contar a atmosfera de mistério que permeia os textos, aquecendo o leitor para as porvindouras cenas de tensão. Tudo de forma a contribuir para os decisivos "momentos de crise de identidade" das personagens, conforme pontuou a professora Gotlib, pois são estas crises que imprescindivelmente constituem a tônica desses objetos textuais.

Importa considerar que, no desfecho dos contos, encontra-se, também, outro relevante traço de similaridade.

Ana, depois do jantar, tendo naquela tarde experienciado "alguma coisa tranqüila" que "se rebentara" dentro dela, vê-se por alguns instantes tomada nos braços do marido:

É hora de dormir, disse ele, é tarde. Num gesto que não era seu, mas que pareceu natural, segurou a mão da mulher [...].

E, enquanto o marido a aguardava, a personagem

penteava-se [...] diante do espelho, por um instante sem nenhum mundo no coração. Antes de se deitar, como se apagasse uma vela, soprou a pequena flama do dia. (p. 25)

No conto "Bliss", Berta, ao regressar à sua casa naquele final de tarde, também se defrontou com a própria imagem refletida no espelho:

Mal se aventurava a olhar para o espelho frio mas olhou, e ele lhe mostrou a imagem de uma mulher radiante, de lábios trêmulos e sorridentes, com grandes olhos escuros e um ar de quem escuta, de quem espera que aconteça alguma coisa... alguma coisa divina... que ela sabe que deve acontecer... infalivelmente. (p. 2)

De fato, "alguma coisa" a mais estaria por acontecer à personagem, além do que seria aquela vital experiência frente à "esguia árvore florida". É que, próximo ao desfecho da história, Berta é surpreendida ao flagrar um "velado diálogo" entre Harry (o marido) e a amiga. Justamente naquela noite, em que tencionava passar felizes momentos ao lado dele, "juntinhos no quarto escuro na cama quente..." $\mathrm{E}$, no entanto, o que ouve é aquela voz:

"Eu te amo", e Miss Fulton pôs os dedos de luar nas faces dele e sorriu o seu sorriso sonolento. As narinas de Harry palpitaram; os lábios se the fecharam crispados num ricto horrendo, quando ele cochichou: "Amanhã". E com as pálpebras Miss Fulton fez: "Sim". (p. 14)

Decerto, tal qual a personagem de Clarice, que no final do conto permanece indecisa diante do espelho, sem saber como the seria o dia seguinte, 
Berta, coincidentemente, encontra-se em semelhante impasse após a cena flagrada entre o marido e a amiga, a ponto de - numa atitude um tanto desesperada - correr para as janelas:

- Oh, que será que vai acontecer agora? - gritou.

Mas a pereira estava tão linda como sempre, e como sempre florida e tranqüila. (p. 15)

Assim termina o conto.

\section{BAKHTIN: O EUE O OUTRO}

A natureza da relação eu e outro, o ver-se a si mesmo através de um dado objeto, ou do olhar deste objeto, que desempenha papel análogo ao do espelho, tornou-se um dos temas centrais dos estudos do historiador de literatura e filólogo Mikhail Bakhtin (1895-1975).

Em ensaios datados entre 1918 e 1924, já se faziam presentes as primeiras preocupações do autor com essa intrigante relação, que, embora em voga na época, passava a ter uma especial ressonância na visão do teórico russo, pois, segundo Robert Stam, "Bakhtin argumenta que cada um de nós ocupa um lugar e um tempo específicos no mundo, e que cada um de nós é responsável, ou 'respondível' por nossas atividades. Essas atividades ocorrem nas fronteiras entre o eu e outro, e portanto, a comunicação entre as pessoas tem uma importância capital. $\mathrm{O}$ eu, para Bakhtin, não é autônomo nem monádico, o cogito autocriàdor de Descartes; em vez disso, existe somente em diálogo com outros eus. $O$ eu necessita da colaboração de outros eus para poder definir-se e ser 'autor' de si mesmo.[...] $O$ eu humano, por analogia, não tem existência independentemente; depende do meio ambiente social, que estimula sua

(7) Robert STAM, "A descoberta do diálogo", in Bakhtin: da teoria literária à cultura de massa, trad. Heloísa Jahn, São Pauto, Ática, 1992, p. 17 (Série Temas, v. 20). (8) Idem, ibidem, p. 18. capacidade de mudança e resposta." $\mathrm{E}$ mais: "Toda a obra de Bakhtin gira em torno desse eixo do eu e do outro, e da concepção de que a vida é vivida nas fronteiras entre a particularidade de nossa experiência individual e a autoexperiência de outros. Para Bakhtin, o eu não está 'lacrado': ele é capaz de atravessar a fronteira e de imaginar o outro como sujeito e ver a si mesmo como objeto."

Em seu livro Problemas da Poética de Dostoiévski, Bakhtin, ao adotar o conceito de polifonia para nomear a multiplicidade de vozes que se fazem ouvir no romance, ou seja, as vozes do autor e do herói, as vozes sociais, bem como de outros gềneros imbricadas no objeto estético literário, acrescenta que o herói se ilumina através de sua autopercepção, olha para si mesmo através do espelho da consciência de outras pessoas, do julgamento que este outro faz acerca dele. Porque, para o teórico, a "autoconsciência do herói em Dostoiévski é totalmente dialogada: em todos os seus momentos está voltada para fora, 
dirige-se intensamente a si, a um outro, a um terceiro. Fora desse apelo vivo para si mesma e para outros ela não existe nem para si mesma."'

Em Questões de Literatura e de Estética, Bakhtin não deixa também de pontilhar sua linha de análise com a questão do espelhamento, uma vez que apreende a linguagem, em sua concretude, como "materialização das ideologias" predominantes num dado tempo e espaço social. Ao dialogar nesta obra com os formalistas, sem, contudo, ter herdado destes o radicalismo no que respeita ao limitado estudo intrínseco do artefato estético, restrito à análise da estrutura do tecido narrativo, Bakhtin lança interessantes reflexões sobre a obra de arte, o ato criador, o contemplador e a cultura, que, impreterivelmente, se interrelacionam:

Quando um escultor trabalha o mármore, indiscutivelmente ele também o prepara na sua determinação física, mas não é sobre ele que está dirigida a atividade artística valorizante do criador, e não é a ele que se refere a forma realizada pelo artista, ainda que a própria elaboração não se realize um único momento sem o cinzel, que de forma alguma entra no objeto artístico como seu elemento; a forma escultural criada é a forma esteticamente significativa do homem e do seu corpo; a intenção da criação e da fruiçâo caminha nesse sentido; mas a relação do artista e do espectador com o mármore, como um corpo físico definido, tem um caráter secundário, derivado, regido por uma certa relação primária com os valores objetais, no caso em questão, com os valores do homem corpóreo. ${ }^{10}$

No capítulo em que trata do "problema do conteúdo", assim considera:

Este ou aquele ponto de vista criador, possível ou realizado de fato, só se toma necessário e indispensável de modo convincente quando relacionado com outros pontos de vista criadores: só quando nas suas fronteiras nasce a necessidade absoluta desse ponto de vista, em sua singularidade criativa, é que ele encontra seu fundamento e sua justificação sólida; mas no seu próprio interior, fora da sua participação na unidade da cultura, ele é apenas um mero fato; e sua singularidade pode ser representada simplesmente como um arbítrio, como um capricho.

Não se deve, porém, imaginar o domínio da cultura como uma entidade espacial qualquer, que possui limites, mas que possui também um território interior. Não há território interior no domínio cultural: ele está inteiramente situado sobre fronteiras, fronteiras que passam por todo lugar, através de cada momento seu, e a unidade sistemática da cultura se estende aos átomos da vida cultural, como o sol se reflete em cada gota. Todo ato cultural vive por essência sobre fronteiras: nisso está sua seriedade e importância; abstraído da fronteira, ele perde terreno, torna-se vazio, pretensioso, degenera e morre."

(10) Mikhail BAKHTIN, "Crítica da arte e estética geral", in Questões de Literatura e de Estéfica: a teoria do romance, trad. Aurora F, Bernardini c outros, 3a. ed., São Paulo, Hucitec, 1993, p. 20.

(It) Idem, ibidem, p. 29. 


\section{VOZES DO ESPELHO}

A relação/interação eu e outro, que Bakhtin estende para mais de uma esfera da vida e do conhecimento humano, assume importância nodal nos dois contos em estudo, haja vista os relevantes papéis que os personagens secundários (sujeitos externos mas ao mesmo tempo internos das narrativas) exercem sobre as personagens Berta e Ana. Na realidade, são eles que conduzem as protagonistas, conforme anunciamos, ao mergulho mais profundo no próprio $e u$, num território desprovido de falsas aparências. Ou seja, é o espelho sujeito quem ocupa, com muito mais vigor, o lugar do objeto espelho no qual elas se olham num dado momento das histórias. Certamente são estes sujeitos outros o cego, Miss Fulton, os maridos, o Jardim Botânico, a pereira os verdadeiros responsáveis pela intensa autocontemplação das duas mulheres, que, ao mirarem o outro, passam a enxergar o que insistiam em manter oculto: as desgastadas relações no âmbito da vida privada, conjugal e social.

Afinal, o cego fez refletir em Ana a plena escuridão, porque é como cega que passa a se ver, uma vez condicionada a conservar-se no papel de mãe e esposa, resguardada num apartamento onde abriga um "verdadeiro" marido, também aparentando desempenhar seu "autêntico papel", e filhos que não deixam, pois, de apresentar típicas características de filhos... Em meio a esse ordeiro estado, só mesmo o Jardim Botânico, no auge de sua serena mutabilidade, poderia levá-la a compartilhar uma evolutiva existência, que ultrapassa os limites da vida regrada. Ele, o Jardim, espelha um mundo selvagem, em abrupto desenvolvimento, que, tal como a vida, origina inesperados malestares.

Sob similar perspectiva, a pereira florida afigura-se como espécie de objeto-espelho: espelho da feminilidade, a ser contemplado por Berta como "o símbolo de sua própria vida". Como tal, apresenta suscetíveis periodos de florescimento, mobilidade e, também, imobilidade frente a dificeis e estridentes momentos do viver. Em momentos como aquele, em que a protagonista flagrara a intima conversa entre Miss Fulton e Harry, até porque a amiga e o marido não deixam de espelhar a deterioração conjugal que Berta evita enxergar, empenhando-se em ocupar parte de seus dias com passeios e preparativos que, provavelmente, garantiriam a casa tomada por amigos. Ademais, a constante presença de amigos não seria uma alternativa encontrada pela personagem para resgatar a "trincada" relação afetiva?

Aliás, em ambos os jantares no jantar de "Amor" e de "Bliss" buscase reatar com a presença do outro, no lar de cada uma das protagonistas, o que na verdade se tornaram frouxos laços de familia, praticamente desatados, mas que espelham, acima de tudo, pulsivas vidas... envoltas em silenciosos conflitos. 
Apropriando-nos de um ponto de vista baklitiniano, dirfamos que tanto um quanto outro conto se configuram como verdadeiras obras de arte. Cada qual se apresenta como obra viva,

viva e literalmente significativa enquanto obra de arte, nåo no nosso psiquismo; nele ela também está apenas empiricamente presente como um processo psíquico, localizado no tempo e regido por leis psicológicas. A obra é viva e significante do ponto de vista cognitivo, social [...], num mundo também vivo e significante. ${ }^{12}$

(12) Idem, Ibldem, p. 30.

ABSTRACT: It's a study comparing the short stories "Amor" by Clarice Lispector and "Bliss" by Katherine Mansfield. A theoretical support is given by Mikhail Bakhtin, a literature historian, in his studies about dialogism and poliphony to both narratives' analyses, whose main characters are wives from a medium burghership that let appear their private existential conflicts when face unusual experiences. KEYWORDS: Feminine; Intertextuality; Bakhtin; Dialogism; Poliphony

Texto elaborado para a disciplina Mikhail Bakhtin e a Teoria da Narrativa, ministrada pela Profa. Dra. Aurora Fomoni Bemardini, no primeiro semestre de 1995. 